\title{
Assessment of Serum Electrolytes in Japanese Encephalitis Patients
}

\author{
Authors

\section{Dr Malavika Barman ${ }^{1}$, Dr Mousumi Borgohain Borah ${ }^{1}$, Dr Mauchumi Saikia Pathak ${ }^{2}$, Dr Rashmi Rasi Datta ${ }^{3}$} \\ ${ }^{1}$ Assistant Professor, Department of Biochemistry, Gauhati Medical College \& Hospital, Guwahati \\ ${ }^{2}$ Professor and HOD, Department of Biochemistry, Tezpur Medical College \& Hospital, Bihaguri, Tezpur \\ ${ }^{3}$ Manager - Autochemistry and Special Chemistry, Quest Diagnostics, India \\ Corresponding Author \\ Dr Mousumi Borgohain Borah \\ Assistant Professor, Department of Biochemistry, Gauhati Medical College \& Hospital, Guwahati
}

\begin{abstract}
Introduction: Japanese encephalitis (JE) is a common mosquito borne viral encephalitis. Most infections of $J E$ are asymptomatic but if clinical illness develops, it causes significant morbidity and mortality.

Aims and Objectives: To assess the serum electrolytes $\left(\mathrm{Na}^{+}\right.$and $\left.\mathrm{K}^{+}\right)$in diagnosed cases of Japanese Encephalitis.

Materials and Methods: The study was carried out in Gauhati Medical College and Hospital, Guwahati, India between January, 2014 and July, 2015. Serum sodium and potassium levels in 100 diagnosed patients of Japanese Encephalitis was assayed in Vitros 5600 Analyser of Ortho Clinical Laboratories by the slide method that uses direct potentiometry for analysis of the ions. Equal number of age and sex matched healthy individuals were taken as control group.

Results and Observations: The present study shows that there is highly significant decrease in the serum sodium levels in the study group as compared to the control group (**p<0.001). On the other hand, there is no significant difference in potassium levels between the study group and the control group ( $p>0.05)$.

Discussion: There is highly significant decrease in the values of serum sodium levels in cases of Japanese Encephalitis, which may occur as a consequence of SIADH.

The findings of the present study thus have an impact in the treatment protocol, as hyponatremia impairs cerebrovascular reactivity. Maintenance of serum sodium level at the ideal level will lead to a significant decrease in both mortality and morbidity.
\end{abstract}

Keywords: Hyponatremia, Japanese Encephalitis, Serum potassium, Serum sodium.

\section{Introduction}

Japanese encephalitis (JE) is a common mosquito borne viral encephalitis found in Asia. ${ }^{1}$ Most infections of JE are asymptomatic but if clinical illness develops, it causes significant morbidity and mortality. It is numerically one of the most important causes of Acute encephalitis syndrome (AES) not only in Asia but also all over the world. ${ }^{2}$ It has been controlled effectively through national vaccination programs in several countries like Japan, Korea, China and Thailand. ${ }^{3-5} \mathrm{JE}$ is endemic in Assam (India) with outbreaks every year during the 
monsoons. ${ }^{6,7}$ There is significant morbidity and mortality due to JE in Assam with as many as 1343 cases and 229 AES-related deaths in $2012 .^{8}$

Japanese encephalitis virus (JEV) belongs to the genus Flavivirus in the family Flaviviridae. ${ }^{9}$ JEV particles are small particles $(-50 \mathrm{~nm})$, in which a glycoprotein-containing lipid envelope surrounds the capsid, which has a single-stranded positivesense 11-kb RNA genome. The viral RNA carries a single open reading frame with genes for three structural proteins, i.e., capsid (C), premembrane (prM), and envelope (E), and seven nonstructural (NS) proteins, i.e., NS1, NS2a, NS2b, NS3, NS4a, $\mathrm{NS} 4 \mathrm{~b}$, and NS5. ${ }^{10}$ It is maintained in a zoonotic cycle involving pigs, ardeid birds and Culex species of mosquitoes. Humans are accidental/dead end hosts of JEV infection because they cannot sustain high viral titers. ${ }^{11}$

Japanese B encephalitis (JBE) is an acute encephalomyelitis. $^{12}$ The manifestations of the disease depend on which part of the nervous system is affected. The course of the disease can be divided into three stages: (i) a prodromal stage preceding CNS features, (ii) an encephalitis stage marked by CNS symptomatology, and (iii) a late stage noticeable by recovery or persistence of signs of CNS injury. Prodormal symptoms consist of nonspecific febrile illness like fever, myalgia, diarrhea etc. It is followed by early CNS symptoms such as reduced levels of consciousness, seizures, headache, photophobia, and vomiting. Symptoms in the later CNS stage include poliomyelitis-like flaccid paralysis and parkinsonian syndrome, which manifests the classic description of JE-dull, flat, mask-like face with wide, unblinking eyes; tremor; generalized hypertonia; cogwheel rigidity; and other abnormalities in movement. ${ }^{13,14}$ Severe encephalitis is associated with a higher frequency of seizures. ${ }^{15}$ In fatal cases, patients ultimately slip into an acute coma. The failure of the host to produce antibodies against the virus is associated with an increased likelihood of the disease to turn lethal. ${ }^{16}$ Many survivors of JE acquire neuropsychiatric sequelae with cognitive and language impairment, in which case the disease presents itself not only as a killer but also as a cause of an immense social and financial burden, especially for a developing country ${ }^{17,18}$ Thus, any addition or change in existing treatment protocol that reduces the disease burden is of significant importance. Studies have shown that fluid and electrolyte imbalance significantly increased the morbidity and mortality in critically ill patients. ${ }^{19,20}$ Hence, in this study we assessed serum electrolytes $\left(\mathrm{Na}^{+}\right.$and $\left.\mathrm{K}^{+}\right)$in diagnosed cases of Japanese Encephalitis to determine if there exists any electrolyte imbalance in such cases, as its correction would significantly bring down the disease morbidity and mortality.

\section{Materials and Methods}

The study was carried out between January, 2014 and July, 2015. Serum sodium and potassium levels in 100 diagnosed patients of Japanese Encephalitis was assayed in Vitros 5600 Analyser of Ortho Clinical Laboratories by the slide method that uses direct potentiometry for analysis of the ions. Only records of sodium and potassium values done within 7 days of onset of encephalopathy were included in the study. Normal sodium level is taken as 137 $145 \mathrm{mmol} / \mathrm{L}$ and potassium level is taken as $3.5-5$ $\mathrm{mmol} / \mathrm{L}$ when tests are done in VITROS 5600 autoanalyser. Only patients more than 18 yrs of age, from either sex were included in the study. Patients having $h / o$ renal disease, diarrhoea, diabetes mellitus, neoplasia and any other such disease/condition that have a proven effect on electrolyte levels were excluded from the study. Equal number of age and sex matched healthy individuals were taken as control group.

\section{Results and Observations}

100 diagnosed cases of Japanese encephalitis were included in the study after evaluation with the inclusion and exclusion criteria. Of these, 32 were female and 68 male patients. 40 female and 60 male persons were included in the control group. 
Age Distribution of the Study Group and Control Group

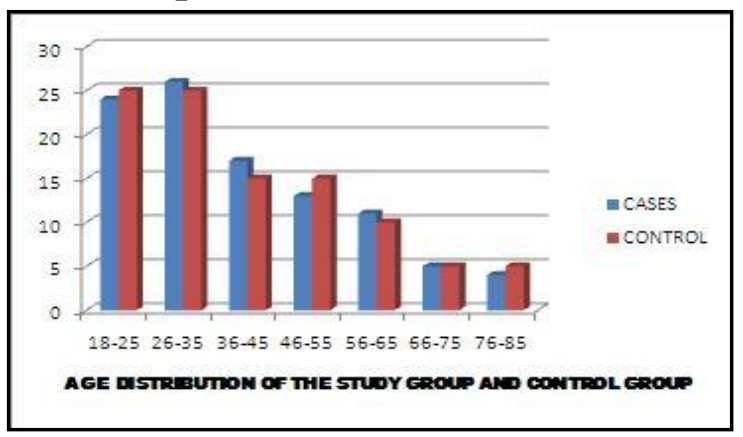

\section{Serum Sodium Values of Study Group and Control Group}

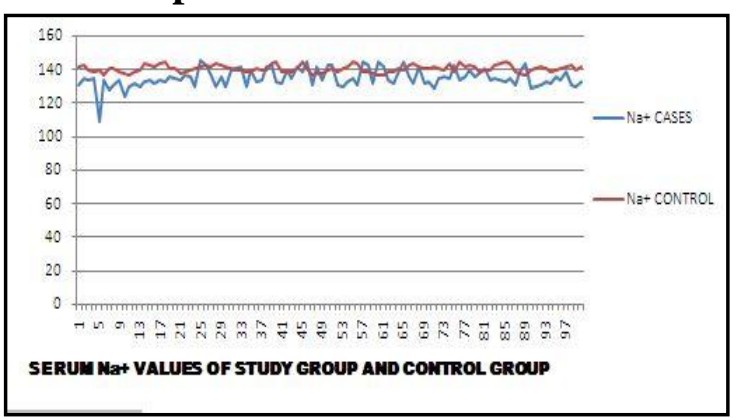

Serum Potassium Values of Study Group and Control Group

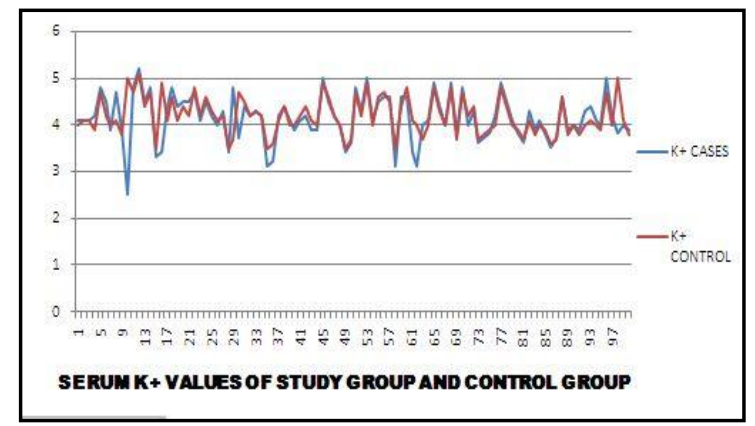

Students' unpaired ' $\mathrm{t}$ ' test was done for statistical analysis of significance in Serum sodium $\left(\mathrm{Na}^{+}\right)$and Serum potassium $\left(\mathrm{K}^{+}\right)$levels in study group and control group. $=$

\begin{tabular}{|l|r|r|r|r|}
\hline & $\begin{array}{r}\text { Na+ Study } \\
\text { Group }\end{array}$ & $\begin{array}{r}\text { Na+ Control } \\
\text { Group }\end{array}$ & $\begin{array}{r}\text { K+ Study } \\
\text { Group }\end{array}$ & $\begin{array}{r}\text { K+ Control } \\
\text { Group }\end{array}$ \\
\hline Mean & 135.25 & 140.86 & 4.154 & 4.192 \\
\hline Standard Deviation & 5.435 & 2.151 & 0.4951 & 0.3992 \\
\hline Std. Error of Mean(SEM) & 0.5435 & 0.2151 & 0.04951 & 0.03992 \\
\hline $\begin{array}{l}\text { Lower 95\% Confidence } \\
\text { Limit }\end{array}$ & 134.17 & 140.43 & 4.056 & 4.113 \\
\hline $\begin{array}{l}\text { Upper 95\% Confidence } \\
\text { Limit }\end{array}$ & 136.33 & 141.29 & 4.252 & 4.271 \\
\hline Minimum & 109 & 137 & 2.5 & 3.5 \\
\hline Median (50th Percentile) & 134 & 141 & 4.15 & 4.1 \\
\hline Maximum & 146 & 145 & 5.2 & 5.1 \\
\hline pvalue & $<0.001$ & & $>0.05$ & \\
\hline Significance & HS & & NS & \\
\hline
\end{tabular}

\section{Discussion}

About $30 \%$ of patients admitted to hospital with Japanese encephalitis die, and around half of the survivors have severe neurological sequelae. In this study, there was male predominance in the occurrence of the disease within both the groups. Previous studies also has similar finding. ${ }^{21,22}$. It might be due to the fact that men-folk remain outdoors more, making them more vulnerable to mosquito bites. In respect to the sodium and potassium levels, the present study showed that there is highly significant decrease in the serum sodium levels in the study group as compared to the control group $(\mathrm{p}<0.001)$. On the other hand, there is no significant difference in potassium levels between the study group and the control group $(\mathrm{p}>0.05)$.

\section{Conclusion}

The highly significant decrease in serum sodium levels in JE cases may occur as a consequence of inappropriate antidiuretic hormone secretion (SIADH). The findings of the present study, thus, have an impact on the treatment protocol in Japanese Encephalitis as hyponatremia impairs cerebrovascular reactivity. Serum sodium level should ideally be maintained above $140 \mathrm{mmol} / \mathrm{L}$. Thus, maintenance of serum sodium level at the ideal level will lead to a significant decrease in both mortality and morbidity. Future scope of the study lies in doing a multi-centric study for a longer period of time.

\section{References}

1. Rao PN. Japanese encephalitis. Indian Pediatrics. 2001; 38: 1252-1264.

2. Japanese Encephalitis: Bangladesh Perspective: A Review Sultana M Hussain , A R M Saifuddin Ekram , M J Hossain , E Gurley , S Lubey . TAJ June 2004; Volume 17 Number 1

3. Tsai TF. New initiatives for the control of Japanese encephalitis by vaccination. Minutes of a WHO/CVI meeting, Bangkok, 
Thailand, 13-15 October 1998, Vaccine 2000: 18: 1-25.

4. Rodhain F. Recent data on the epidemiology of Japanese encephalitis. Bull Acad Natl Med 1996; 180: 1325-1340.

5. Rojanosuphot S, Tsai TF. Regional Workshop on Control Strategies for Japanese Encephalitis. Southeast Asian J Trop Med Pub Health 1995; 26: (S3): 1-59.

6. Reuben R, Gajanana A. Japanese encephalitis in India. Indian $\mathbf{J}$ Pediatr 1997;64:243-51

7. Patgiri SJ, Borthakur AK, Borkakoty B, Saikia L, Dutta R, Phukan SK. An appraisal of clinicopathological parameters in Japanese encephalitis and changing epidemiological trends in upper Assam, India. Indian $\mathrm{J}$ Pathol Microbiol 2014;57:400-6.

8. Directorate of National Vector Borne Disease Control Programme, Delhi. Details of AES/JE Cases and Deaths from 2008-

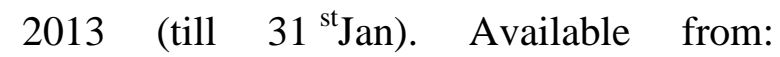
http://www.nvbdcp.gov.in/Doc/je-aes-cdtillJan13.pdf (Last accessed on: 27.02.2013).

9. Pareek S, Roy S, Kumari B, Jain P, Banerjee A, Vrati S. MiR-155 induction in microglial cells suppresses Japanese encephalitis virus replication and negatively modulates innate immune responses. Journal of neuroinflammation. 2014 May 29;11(1):97.

10. Lindenbach BD, Thiel Heinz-Jurgen Rice CM. 2007. Flaviviridae: the viruses and their replication, p 1101-1152. In Knipe DM, Howley PM (ed), Fields virology, 5th ed, vol 1. Lippincott-Raven Publishers, Philadelphia, PA

11. Unni SK, Růžek D, Chhatbar C, Mishra R, Johri MK, Singh SK. Japanese encephalitis virus: from genome to infectome. Microbes and Infection. 2011 Apr 30;13(4):312-21.

12. Abe, T., Kojima, K., Shoji, H., Tanaka, N., Fujimoto, K., Uchida, M., Nishimura, H., Hayabuchi, N. and Norbash, A. M. (1998), Invited. Japanese encephalitis. J. Magn.
Reson. Imaging,

8: 755-761.

doi: 10.1002/jmri.1880080402

13. Solomon T, Dung NM, Kneen R, Gainsborough M, Vaughn DW, et al. (2000) Japanese encephalitis. J Neurol Neurosurg Psychiatry 68: 405-415.

14. Solomon T, Kneen R, Dung NM, Khanh VC, Thuy TT, et al. (1998) Poliomyelitis-like illness due to Japanese encephalitis virus. Lancet 351: 1094-1097.

15. Solomon T (2004) Flavivirus encephalitis. N Engl J Med 351: 370-378

16. Burke DS, Lorsomrudee W, Leake CJ, Hoke $\mathrm{CH}$, Nisalak A, et al. (1985) Fatal outcome in Japanese encephalitis. Am J Trop Med Hyg 34: 1203-1210.

17. Vaughn DW, Hoke CH Jr (1992) The epidemiology of Japanese encephalitis: prospects for prevention. Epidemiol Rev 14: 197-221.

18. Kaur R, Vrati S (2003) Development of a recombinant vaccine against Japanese encephalitis. J Neurovirol 9: 421-431.

19. Lee JW. Fluid and electrolyte disturbances in critically ill patients. Electrolyte Blood Press. 2010;8:72-81.

20. Funk GC, Lindner G, Druml W, et al. Incidence and prognosis of dysnatremias present on ICU admission. Intensive Care Med. 2010;36:304-311.

21. Umenai T, Krzysko R, Bektimirov A., Assaad FA. Japanese encephalitis: current world status.WHO Bulletin OMS 1985; 63: 625-631

22. Reuben, R. \& Gajanana, A. Indian J Pediatr (1997)

64: 243. https://doi.org/10.1007/BF02752458 